\title{
ENTREPRENEURIAL CREATIVITY AND INNOVATION MANAGEMENT IN ENGINEERING
}

\author{
TRIFAN, L[aura]; GUICA, R[aluca] I[oana] \& MICU, C[onstantin]
}

\begin{abstract}
Creativity and Innovation are the two pillars of modern companies and institutions; they offer competitive advantage on the market and economic growth. The authors propose a concept of creativity and innovation training for engineering, starting with consultancy for technical problem solving, continuing with trainings (Training of Trainers and courses for graduates and entrepreneurs), based on creativity techniques and management topics, forming not just entrepreneurial behaviors, but entrepreneurial attitudes for engineering employees (intrapreneur). SMEsof the engineering branch are the beneficiaries of consultancy and trainings on these issues. Beside the creativity and innovation management courses for students, the Technical University "Politehnica" of Bucharest provides a large range of courses and flexible training modules for graduates and entrepreneurs as well. Creativity in engineering is different from creativity in other domains of activity.

Among other activities, the Technology Transfer and Innovation Center for SMEs is researching and adapting creativity techniques for engineering. This paper demonstrates the acute need of a specialized literature on creativity techniques for engineering. The large amount of references from psychology has to be firstadapted and then appliedto technical issues. One example of adaption is the "ad-hoc brainstorming"among researcher teams.

Keywords:Innovation Management, Creativity techniques, intrapreneur-entrepreneur, curriculum
\end{abstract}

\section{INTRODUCTION}

Creativity in technology and engineering is the main issue for successful competitive advantage and economic growth of the companies and generally for modern insitutions. The answer to the question"how much process and how much surprise are in creativity and in idea generation" [4] gives a better understanding of the options to train the innovation and creativity skills in the technical SME and helps these to manage innovation in their own company.

The term "creativity" is usually associated with art, design, management, social sciences. Technical creativity is rather tacitly associated with its "radical" results - the "revolutionary" inventions, which change large parts of the society and ofmentalities, habits, theirand life in general. Two decades are not much time for changing the mentalities of a society, along with the transformations of the economy. Market economy and EU-membership brought some major changes in the social and economic relations within the society and also in the way of perceiving the market principles. Big stateowned companies had either change or die, the engineering branch is investment intensive, so that their only chance was to get flexible and learn how to bring new ideas and products on the market and how understand the customers' needs.

The Technical University "Politehnica" of Bucharest offers a mix of courses for industrial creativity and innovation stimulation and development of entrepreneurial skills for graduates and entrepreneurs. The University provides courses for the improvement of creativity in engineering and allows a feed-back on the shortest way from the SMEs of the technical branch, by analyzing their training needs and adapting the courses in time and content to the specialization demands of the SME representatives (both entrepreneurs and employees). The communication between the university and the engineering specialists of the SMEs takes place within interactive events like workshops and seminars. The place arrangement is an essential issue for an easy idea and opinion exchange. The form which allows a better way of communication is the U-shaped trainingroom, where all participants are "in the first row" and have a direct contact to all the other participants and to the central point where the moderator is facilitating the discussions. Another aspect about the importance of the place regards the organization of the departments. Is the open-space the best solution for being creative in a technical team, are the informal discussions useful for providing unexpected associations of ideas and in the next stage, a proper solution, or not.All these questions and many other, especially those regarding the protection of intellectual property, the financing of innovation and the shortest way to commercialization of the results of creative thinking need to get answers in a proper framework.

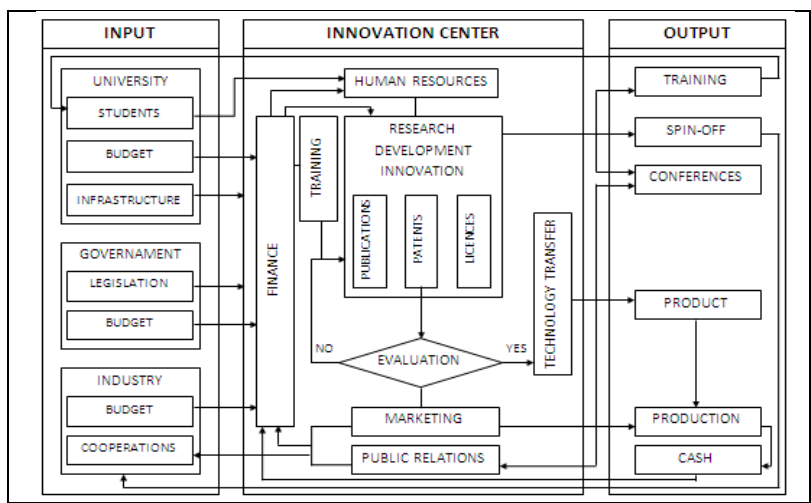

Fig. 1. Model of Technology Transfer\&Innovation Center for SME

The model of the Technology Transfer and Innovation Center (for SMEs) at the Technical University "Politehnica" of Bucharest is a flexible structure that can be particularized for different 
engineering specializations [20]. Zooming out the training output of the center, this paper presents highlights of modern and innovative curricula for increasing competitiveness for the SMEs. Beneficiaries are the representatives of SMEs, who attend specialized courses for developing and fostering their engineering knowledge, with knowledge about creative and innovative thinking. Out of a large range of creativity techniques, the authors chose the brainstorming to illustrate the assumption that creativity techniques for engineering need to be adapted for using their whole potential.

Combining entrepreneurial skills with intrapreneurship (although the concept "Intrapreneur" or "Intracorporate Entrepreneur" is not new, it has been coined by Gifford Pinchot in 1985) and with a "rebranded" version of brainstorming (among other creativity techniques) generates a mix of applicationswhich produces new insights for the beneficiaries (SMEs attending the creative engineering courses within the Technology Transfer Center), as a form of coaching for business excellence. The trainers and coaches are actually facilitators, they are not persons who teach, but who provoke the participants to "dig out" and express their own ideas and conceptions about the issues discussed.

Curricula for existing SMEs, who strive for market survival and for differentiation (unique selling feature of products and adjacent services) in their market-oriented strategy is helpful in coordinating their creativity potential and offering useful instruments to be "taken away" and applied into their company. The original contribution of the authors is in proposing some insights for a concept of curriculum, as a fusion of the poles intrapreneur-entrepreneur and the conceptualexperiential creativity, based on a long term study (2008-2011) among participants to the trainings for "Development of entrepreneurial skills" and students of the Faculty of Industrial Engineering in German Language at the Technical University "Politehnica" of Bucharest[21]. From the variety of creativity techniques, the present paper shows highlights about the Brainstorming, a well-known method, commonly used for gathering ideas in many domains of activity, improved and adapted to the new demands of the engineering branch.

\section{CREATIVITY AND INNOVATION}

Creativity is the production of novel and useful ideas in any domain.Entrepreneurial creativity is "the implementation of novel, useful ideas to establish a new business or new program to deliver products or services" [1]. Creativity can be conceptual or experimental and these patterns were empirically established, by a large number of studies in arts and extending results to economic research to creativity, although it may be sometimes difficult to measure "the creative life cycles of entrepreneurs, because the innovations of individuals cannot always be disentangled from those of others within firms".

In the opinion of Galeson, the study of creativity in economy is a new activity and that the economic analysis of creativity may have application in other domains [8]. In the authors'opinion, creativity is the source of integrative models for every domain. Very interesting are the integrative models of engineering, management and marketing.

The conceptual creativity is about bringing not existing ideas, deductively, to reality and experimental creativity means building a contribution inductively from perception and observation. Both types are needed in the process of innovation, but on different paths. Conceptual creativity is rather abstract and is more (but not exclusively) related to invention and the experimental creativity more to innovation (marketing, client oriented design) and diffusion.

Only for classification reasons, the technological change is divided by Schumpeter into three phases: invention (the creation of new technologies); innovation (the commercial introduction of new technologies); and diffusion (the spreading of new technologies). In this paper, invention will not be considered, because it represents the domain of radical novelties and it has special requirements [3].

Innovation "is the implementation of a new or significantly improved product (good or service), or process, a new marketing method, or a new organizational method in business practices, workplace organization or external relations. The definition encompasses both technical and management aspects which have to be taken into account by managers and employees.

This definition contains four types of innovation:

1. Product innovation: the introduction of a good or service that is new or significantly improved with respect to its characteristics or intended uses;

2. Process innovation: the implementation of a new or significantly improved production or delivery method. This includes significant changes in techniques, equipment and/or software;

3. Marketing innovation: the implementation of a new marketing method involving significant changes in the 4-7 P's of a product;

4. Organizational innovation: the implementation of a new organizational method in the business practices, workplace organization or external relations [19].

Under the title „The Five Senses of Innovation“, one of the articles of the New Wave of Social Media treates the issueof checking of being innovative. [4] asserts that in evaluating a person's innovativeness, there are three aspects to be taken into consideration. The first is about the fact that "...innovation is a skill, not a gift. It can be trained and learned like any other skill". According to this theory, innovators should be able to "deploy ideation methods - on demand." The second aspect is about the motivation and the hopefulness, as the feeling that stimulates creativity of the employees at work. The third aspect regards the fact whether the innovator has the "five senses of innovation" or not. The model describes the behavior and much more than that, the attitude of an innovator.

1. Internal Sense: the innovator understands the company's current situation, challenges, opportunities, and direction and gains support from leaders regarding budget, headcount, and time. The 
innovator gives and gets reciprocal support to the right people across different functional departments ( $R \& D$, marketing, finance etc.);

2. External Sense: the innovator understands the market segmentation and grasps the competitive factors and especially the critical factors which drive the company to success;

3. Positional Sense: given an understanding of the internal and external factors, the innovator grasps the market position of the company relative to the competition and how innovative products and services help move the company to a more desirable position;

4. Strategic Sense: the innovator has considered various options to achieve success rather than just one "obvious" choice and is insightful enough to consider the less obvious or hidden options;

5. Value Creation Sense: the innovator tied the recommended course of action to value creation for the companyhe is realistic about the recommended course of action and the risk involved and shows a real sense of concern and ownership of the fit and impact of the recommended idea.

The model presents multiple aspects and the complex involvement of an innovator as one of the driving forces in an enterprise. The innovative behaviour evolves to an attitude, as far as innovators follow up the entire process from the idea of a product to the after sales support and services.

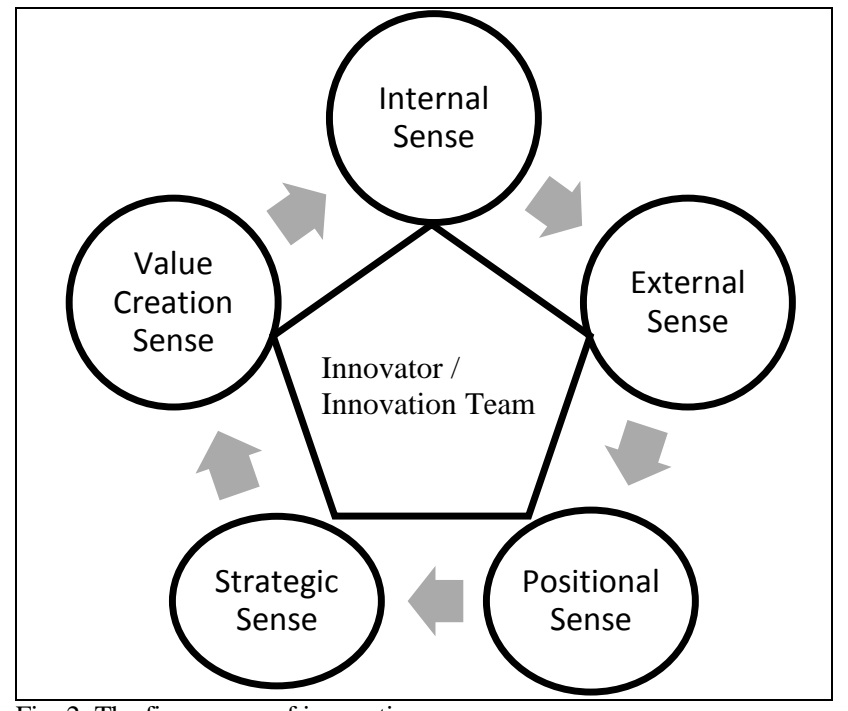

Fig. 2. The five senses of innovation

Too often, discussions, theories, trainings and conclusions are settled around the concepts "Entrepreneurship" and "Entrepreneur". Another interesting and important concept is the Intrapreneurconcept, meaning that an employee treats the company as his own and acts about his projects under a total commitment, but only if there is a conviction that his idea is in consonance with his values and his imagination. This gives the innovator "the guts to act as if he could any minute get fired, disobbeying some organizational rules if necessary and putting resources in motion for making the idea come true" [17].The consequences of intrapreneurship are growth and profitability. The four dimensions of Intrapreurship are: new business venturing, innovativeness, self-renewal, proactiveness [2]. The person practices them in the company and sometimes this is the basis for a spin-off.

\section{3. "OLD” AND "NEW"BRAINSTORMING}

\section{1 "Old" Brainstorming}

Creativity techniques are well developed in the psychology literature. The four classical rules of brainstorming proposed by Alex Osborn in ' 48 are:

1. don't criticize;

2. quantity is wanted;

3. combine and improve the suggested ideas;

4. say all ideas that come to mind [16].

One essential question is to how to choose the most adequate techniques for engineering and how to make them provide the best results for solving technical problems. Experience provides some useful techniques, but as research develops, innovation is also needed in this field.For preliminary idea gathering, brainstorming is still the most appropriate technique for solving engineering problems.

\section{2 "New" Brainstorming}

This technique is well known, that is the reason why it was chosen in the present paper, for illustrating the adaption and improvement for the engineering branch. A newer approach regarding this creativity technique states that dissent is very useful for group creativity. Jonah Lehrer tries to answer to the question "What's the best template for group creativity"? An experiment of Charlan Nemeth in 2003, demonstrated that groups who are given the "debate" condition, produce more ideas in a given time than groups who are producing ideas on classical brainstorming rule basis. According to Nemeth, criticism make people to come up with better ideas, the authentic dissent stimulates production of new ideas. However, people who are afraid of saying wrong things, don't say anything else [13]. It's just that Nemeth's experiment is based on the psychology perspective and needs to be adapted or at least verified in case of applying it in the engineering branch. Her approach was a corroboration of an empirical method that members of the Chair of Mechatronics used to apply when working to their research projects. Each time when a technical problem needs a rapid solution, the colleagues get together and put all possible critics together - the opposite of the classical "recipe" of the brainstorming, together with solution proposals. Forcing some associations, a short list of proper solutions is analyzed in the next step.

In an interview about his most recent book [14], Jonah Lehrer discusses about the creativity of corporations which decreases directly with their size and about the fact that big companies inhibit the natural creativity of the employees because of blocking the social networks and the free idea exchanges among employees. The solution that Jonah Lehrer proposes to "boost the own creativity" is "the embrace of failure", as failure is "an essential component of the creative process". This is the real creativity driver, in his opinion, 
along with playing ping pong or relax, as ideas come easier when one stops searching for them, or with diversifiying the social network, talking to people who think different, or even becoming an outsider and work on problems one is less familiar with. On the other hand, Lehrer's further recommendations to foster creativity in a company are not to brainstorm, but think, debate and dissent and to maximize horizontal interactions. Although the "ad-hoc brainstorming"-method developed and used by the team colleagues, professors and researchers of the Mechatronic Chair at the University "Politehnica" of Bucharest is different in some aspects from Jonah Lehrer's proposed methods, it is a partial confirmation of the authors'opinion that brainstorming combined with debate and dissent is the right path to results in technical projects. In this way over 40 patents came into life out of which 20 have been turned into products.

A long term study on persons who aim to create a small enterprize and attended therefore a 5-days-course for developing entrepreneurial skills, demonstrated that in groups where an element of debate or filtering occurred (e.g. make an association if you agree and give a word of evaluation of the previous idea, if you don't agree) the results of brainstorming is more accurate than the classical form of brainstorming. For each training and an average number of 25 persons coming from very different domains of activity students, employees, small entrepreneurs, unemployed), brainstorming groups were formed splitting them into 4 groups of 5 persons or 3 groups of 6-7 persons. All brainstorming sessions were organized for collecting ideas for small businessesthat could start in their city or region. The next step was to filter the bulk ideas collected during the brainstorming session using further methods: point evaluation method, then macro- and microscreening techniques, and then choose one idea per group and develop a business plan until the last day $\left(5^{\text {th }}\right.$ day) of the training. Sometimes, one round for the brainstorming session was enough sometimes a second round was necessary to get potential applicable ideas and not just follow the brainstorming formalism and get a list of ideas that could not further be developed.

Jonah Lehrer is one of the strong voices who speak against the brainstorming. His experimental research indicates that the results of brainstorm meetings are less productive than when people generate ideas working alone. Although in manufacturing companies, using the brainstorming technique seems to be just a matter of impressing the clients [18].At this point, the authors totally disagree. Individual creativity needs time and is unpredictable. As time is essential in acting on the market, the generation of new ideas is also important for developing new products, so it can't be left in the hands of individuals, who may have an idea or not.

One reason why brainstorming is broadly used is because of it simplicity and the fact that used correctly, with a short preliminary preparation, it can provide reliable results, given some conditions:

1. Encouraging people to list ideas before the brainstorming sessions;
2. Monitoring number of ideas produced by each person;

3. Breaking down the problems and brainstorming components by group members;

4. Taking breakes from each other by group members;

5. Setting high standards for the number of ideas;

Besides, there are some positive features which make the outcomes of a group session more valuable than the individual idea generation [7].

Individual creativity in engineering can not be scheduled. Getting an idea is a spontaneous process that occurs randomly and can never be planned. On the contrary, a group can more likely provide reliable creative solutions on demand. While in arts creativity is a solitary work, in engineering it is much better and more productive to work in groups. The group has to be heterogenous but people should know each other and be able to exchange contradictory opinions. So, the other form of practising brainstorming in academic framework, in the researcher teams, is an adapted form, which has been functioning for decades, in groups where the members know each other well and work together for long time: the "constructive criticism on brainstorm" or "the ad-hoc brainstorming". Every idea is criticized and "demolished" or radically changed, or at least amended by the other colleagues. Nobody gets upset and the group dynamic is extremely high, especially when attempting to solve urgent technical problems, but also in keeping up and stimulate a creative atmosphere. The team members (which are also university professors) agree upon criticizing and being criticized as a way of getting aware of some new perspectives of a certain problem or issue.

\section{MANAGEMENT OF THE INNOVATION COMPLEXITY}

Even if the collection of ideas may be easy, the innovation is harder to realize, because it actually means a change, in mentality, in all the departments of the organization, employees, suppliers, in the procedures and of course in the customer relationship which, according to the experience, cannot be easy internalized. Change management means an adjustment for every new process and aspect in thecompany and deal with the employees to accept all the novelty of procedures and of products. Only a high flexibility and a low resistance to changes can provide solutions for acting properly on the market and create a proper atmosphere in the company. But changing processes and/or procedures may imply new technologies, new personal (meaning higher costs) and new tasks, new relations, maybe new behaviours, which have to be understood and accepted.

The innovation creates the demand for change both inside and outside the company and a vision for a better status quo. In the engineering branch innovation means both innovative products and innovative management (inside and outside the company) (see Fig. 3). 


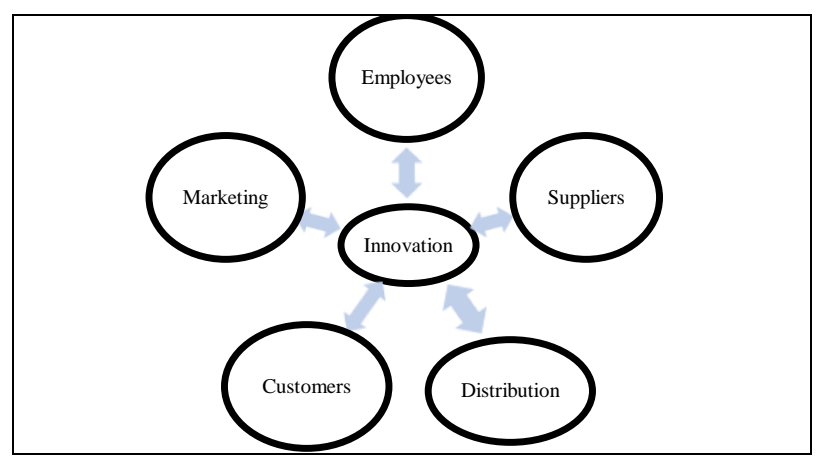

Fig. 3. Push-Pull approach in Change Management

Each innovation means a change. Customers have to imagine the product for themselves. Employees have to do things in a new way. Some major innovation may determine suppliers to make essential changes in order to provide services to their clients [10]. On one side, the company has to successfully focus on developing and providing new and innovative products on the market and on the other side they have to deal with the internal changes and the coordination of all new aspects in the relations with the suppliers and the customers. All actors are involved in the value creation so that customer satisfaction is achieved.

The main capacities for creative engineering are "knowledge acquisition and openness", while some of the tools are brainstorming, communication and sketching skills [11].

One important asset of the entrepreneurial engineer is the synthesis between the qualitative and the quantitative mode of analysis. Quantitative is the technical part of generating, understanding and operating with formulas or diagrams, the technical competence. This is useful when focusing on technical projects and for technical writing, while the qualitative analysis is appropriate for everything related to the business knowledge, encompassing the personal, interpersonal and organizational skills.

Another dual perspective is the concern for technology against the concern for humans [9], necessary to raise awareness for the related aspects. The former is again about the hard engineering skills, the latter is about all the modern aspects of team dynamics, communication,downshifting and flexibility[6]. An example of an alternative way of doing business and yet taking care of the personnelis the brasilian machine production company Semco, where the 3000 employees choose their manager, establish their working time and their salaries, which are viewed by all the others. There are no business plans, no HR-department and almost no hierarchy. They all plan, work and clean together. All profits are distributed by voting, emails are completely private and the employees decide by themselves how much they may spend for business trips or for computers etc. Creativity is the policy of the company (e.g. "the out of your mind"-committee meets from time to time and presents unconventional ideas) and there is no hierarchy in the company, but three concentric management circles. A balance between technology and personnel isideal but as a general principle, the concern for humans should always prevail. The "Semco-way" as the company members use to name it themselves is rather isolate, an experiment to prove the effects of the total individual freedom of expression and of personal decision in the company, as a model of "entrepreneurship with total intrapreneurs".

Some experiments research about the special phenomena which happen with creativity in the proximity of the authors to each other. The results of the research seem to demonstrate that the quality of research increases when coauthors have more "face-time" with their colleagues. This is also called "water cooler effect". Even if the conclusion was that more researches are needed for reconfirming the theory, the most rational conclusion of the apparent correlation between the proximity in the building and the number of citations in the scientific papers is that "Science is all about communicating your ideas so others can build on them" [5].

Another interesting approach regarding unconventional behavior in modeling problems on the way of solving them in a creative way is the so called "napkintalk" [9], a concept proposed by David Goldberg which is a way of connecting visualization and verbal thinking. Important ideas can be sketched on a napkin during an informal discussion.

Actually the discussion necessarily comes to the open innovation topic, which is "about integrating external partners in the entire innovation process" [15]. Why is it essential to involve the external partners into the innovation process? Because the innovation can not be separated from the continuous improvement processes and regarding the just-in-time reaction to the customer's requests is an important differentiating factor on the market. These principles need to be used by all companies, big and small as well.

On the other hand, market has to be well-understood and watched.Two interesting approaches to new marketing techniques are the WOMM (word to mouth marketing) campaigns and putting Influentials to work in Social Media Marketing. Influentials are above average skeptical persons with a strong opinion influence on potential consumers, very active persons on Social Media Networks, who should be convinced to acquire the products of a company because they are able to multiply the effect and convince other potential clients to acquire products of the same company [12].

All the above discussed aspects lead to a better understanding of the complexity of aspects that managers need to understand and cope with, in order to keep the company successful on the market.

\section{THETRAININGOFFER OF THE CENTER}

Flexible curriculaaddress the full time employees, adapted to their schedule.

The course design offers more packages:

1. 1-day courses and workshops for topics like brainstorming and other applicable creativity techniques for engineering, which are just the "peak of the iceberg", only the starting point for further connections to team work, motivation and experiential learning; 
2. 2-5 day-courses about engineering creativity innovation management and financial and accounting skills and skills related to marketing, market research, advertising and promotion;

3. 2-5 days about patent research and patent writing. Improvement and optimization of technical solutions based on existing products is as important as revolutionary ideas. That is the reason why an adequate documentation (patent research) is useful.

SMEs justify that lack of funding is the reason of procrastinating innovative actions. Funds are not exclusively the engine of an innovative approach in the company. Along with the "hard facts", the engineering aspects (e.g. CAD-courses and consultancy for patents, technology transfer), the curricula will encompass a wide range of modern management theories with practical applications of the innovations into the SMEs. Somehow everybody knows the "open secret" that graduatingusually gives a theoretical but not a practical perspective. The Innovation Center is able to provide a wide range of conceptual and experiential creativity issues, to help SMEs as beneficiaries to solve their specific both technical and managerial problems in a new way. The new way means to give a new value and new perspectives to long known approaches.

\section{CONCLUSIONS}

Based on the experience as trainers, university professors and entrepreneurs, the authorsdevelop curricula on creativity and innovation management to be provided into trainings, workshops and courses for SMEs. These companies usually request assistance within the Technology Transfer and Innovation Center for technical issues. On this occasion, SMEs of the engineering branch get trained in modern management and creativity techniques and also in forming entrepreneurial attitudes among their employees. An important advantage of the Center is the fact that companies give their feed-back to the University on the shortest way and all the courses, both for SME employees and for the students can be adjusted and permanently actualized according to the needs of the SMEs.A large amount of data collected in a 3 years research on more than 1.000 trainees of various occupations and domanins of activity led to the conclusion that creativity techniques are important tools for the creative process, which can bemodified and adapted to the different branches of activity, for achieving their full potential.

Adjusting the modern theories on general creativity and innovation to the curricula of the Center for Innovation and Technology Transfer is one of the main tasks within the pilot project: modern approaches for engineers. Besides, other creativity techniques are going to be tested and adjusted for the engineering branch, in a systematic attempt to publish a study about creativity techniques for engineering.

The used method is the facilitation, a different concept from teaching and coaching, it means guiding the participants to their own results, based on their personality, their needs and their creative capacity.

\section{REFERENCES}

[1] Amabile, T.(1996). Creativity and innovation in organizations, Harvard Business School, Note for the MBA courseEntrepreneurship, Creativity and Organization, pp. 1-15

[2] Antoncic B., Hisrich R.(2001), Intrapreneurship. Construct refinement and cross-cultural validation,Journal of Business Venturing, Vol. 16, No. 5, (September 2001),pp. 495-527, ISSN: 0883-9026

[3] Arthur B.The structure of invention (2007), Journal of Research Policy, Vol. 36, No. 2, (March 2007), pp. 274-287, ISSN: 00487333

[4] Boyd D.,http://www.innovationinpractice.com/,Accessed on:2012-06-14

[5] Bradley-Ruder D.(2011), Harvard Magazine, The "water cooler" effect, http://harvardmagazine.com, Accessed on: 2012-06-20

[6] Ekwaro-Osire S., Orono P.(2005), Pan-mentoring in creative engineering design - the coordination of individual and team creativity, 35th ASEE / IEEE Frontiers in Education Conference, 19-22 oct.2005,Indianapolis, pp. 8-18, ISBN: 0-7803-9077-6, IEEE Conference Publications, Indianapolis

[7] Furnham A.(2000),Business Strategy Review, Vol. 11, No. 4, (December 2000); pp.21-28, ISSN: 1467-8616, London Business School

[8] Galenson D. (2010), Understanding creativity, Journal of Applied Economics, Vol. 13, No. 2, (November 2010),pp. 351-362, ISSN:1667-6726, Universidad del CEMA

[9] Goldberg D.E.(2006), TheEntrepreneurial Engineer. Personal, Interpersonal and Organizational Skills For Engineers in a World of Opportunity, Wiley \& Sons, Inc. Hoboken, New Jersey, ISBN: 978-0470007235

[10] Kelley B.(2010). Stoking your Innovation Bonfire: A Roadmap to a Sustainable Culture of Ingenuity and Purpose, Wiley \& Sons, Inc. Hoboken, ISBN: 978-0470621677

[11] Klukken P. G., Parsons J. R., Columbus P. J. (1997), Creative experience in engineering practice: Implications for engineering education, Journal of Engineering Education, Vol. 86, No. 2, (April 1997), pp. 133-138, ISSN:1069-4730, American Society for Engineering Education

[12] Kopp O: http://www.online-marketing-deutschland.de, Accessed on: 2012-07-14

[13] Lehrer J. (2012)Groupthink. The brainstorming myth,http://www.newyorker.com,Accessed on:2012-07-06

[14] Lehrer J.(2012) Imagine: How Creativity Works, Houghton, Mifflin, Harcourt Publishing Company, ISBN: 978-0-547-386072, New York

[15] Lindegaard S.(2010). The Open Innovation Revolution: Essentials, Roadblocks\& Leadership Skills, ISBN: 9780470604397

[16] Olfert K., Steinbuch P. (2002). Kompakt-Training Projektmanagement, Friedrich Kiel Verlag GmbH, ISBN: 9783470485935

[17] Pinchot G., Pellman R. (2000) Intrapreneuring in Action: A Handbook for Business Innovation, Berett-Koehler Publishers, ISBN:978-1576750612

[18] Sutton R., Hargadon A. (1996). Brainstorming Groups in Context: Efectiveness in a Product Design Firm, Administrative Science Quarterly, Vol. 41, No. 4, (December 1996), Johnson at Cornell University,pp. 685-718, ISSN: 0001-8392,

[19] The OECD Innovation strategy, (2010), Available from: www.oecd.org/innovation/strategy, Accessed on: 2012-07-10

[20] Trifan E.L., Guica I.R., Micu C.A.(2012).Innovation Management and Technology Transfer within a Model ofInnovation Center at the University Politehnica of Bucharest,Journal for Problems of Management in the 21st Century, (June-July 2012),pp. 74-85, ISSN 2029-6932, Scientific Methodical Center „ScientiaEducologica“, Lithuania

[21] Trifan E.L.(2012). Development of Entrepreneurial Skills.Case Studies (unpublished) 